\title{
Finn Kydland and Edward Prescott's Contribution to the Theory of Macroeconomic Policy
}

\author{
Guido Tabellini* \\ Bocconi University, I-20136 Milano, Italy \\ guido.tabellini@uni-bocconi.it
}

\section{Introduction}

Finn Kydland and Ed Prescott have transformed the field of macroeconomics with two path-breaking contributions. One is the idea of time inconsistency of optimal policy rules. The second is their analysis of business fluctuations. Both contributions have profoundly changed the way we think about macroeconomic problems, both in academic research and in practical policymaking. But while their analysis of business fluctuations is the result of a research effort that lasted more than two decades, the idea of time inconsistency of policy stems from a single paper, Kydland and Prescott (1977). After writing that paper, Kydland and Prescott have not returned to this topic except in a methodological paper on capital taxation; see Kydland and Prescott (1980). Yet, the idea was so important and powerful as to open up a whole new line of research in macroeconomics, that changed the way we study and implement economic policy. Rarely has a single paper had such a profound effect on economic research and the practice of economic policymaking.

In this paper, I discuss the idea of time inconsistency, how it was formulated by Kydland and Prescott, and why its implications are so important. Section II sets the stage and places the contribution by Kydland and Prescott in the context of the theory of macroeconomic policy. Section III analyses earlier formulations of the notion of time inconsistency. Section IV summarises Kydland and Prescott's contribution and its main implications. Section V briefly considers their impact on subsequent research and Section VI concludes.

\footnotetext{
* I am grateful to Torsten Persson for many discussions on this general topic, over several years. I am the only one responsible for the views expressed in this paper.

(C) The editors of the Scandinavian Journal of Economics 2005. Published by Blackwell Publishing, 9600 Garsington Road, Oxford, OX4 2DQ, UK and 350 Main Street, Malden, MA 02148, USA.
} 


\section{Rational Expectations and the Theory of Macroeconomic Policy}

Like most innovative research in macroeconomics in the postwar period, the contribution of Kydland and Prescott to the analysis of macroeconomic policy evolved from the ideas developed by Robert Lucas in the mid-1970s. Under rational expectations, an economic equilibrium consists of optimal and mutually consistent private decisions, as well as a policy rule that specifies the setting of policy instruments for each state of the economy. Without a policy rule, the economic equilibrium is incomplete, because we do not know how to specify private agents' expectations about future policy. According to Lucas, normative policy evaluation ought to compare alternative policy rules, taking into account how each rule affects private expectations and, ultimately, the economic equilibrium. This formulation of policy analysis is based on a statistical notion of rationality: rational expectations make optimal use of whatever information is available, just like a professional statistician.

This view of a rational expectations equilibrium evolved in the mid-late 1970s, under a more stringent requirement of rationality. Not all policy rules are equivalent: some are more credible than others. Rational private individuals will not believe any policy rule; they will form their expectations by taking into account government incentives and the details of the policy formation process. In other words, they will be rational in a game-theoretic sense, not just in a statistical sense. This more stringent requirement of rationality shifts attention from the normative evaluation of alternative policy rules to the positive question of how policy rules are selected. To give content to rational expectations, we have to ask how policy decisions are reached, what are the policymaker's incentives and constraints, and how these public incentives are perceived by the private sector. An economic equilibrium, under this more stringent definition of rationality, consists of optimal and mutually consistent private decisions, as well as a policy rule which is the equilibrium outcome of a policy selection game. To the extent that the analysis has normative implications, these concern the rules of the policy selection game, namely the institutions that determine how policy decisions are made.

This development in the theory of macroeconomic policy originated from the pioneering paper written by Kydland and Prescott in the mid-1970s. Kydland and Prescott (1977) viewed the policymaker as a single decision maker, maximizing a social welfare function. But policy choice was made sequentially, period by period, rather than once and for all. The focus of the analysis was on the credibility of alternative policy rules. Kydland and Prescott pointed out that policy rules which are optimal from the perspective of an initial date may be "time-inconsistent": they may fail to be selfenforcing and, if believed by the private sector, even a benevolent policymaker could have an incentive to deviate from such rules at later stages. 
Time inconsistency thus implies lack of credibility. An optimal but timeinconsistent policy rule will not be believed by rational private agents, unless the policymaker is really forced to implement it. They also characterised time-consistent policy rules, corresponding to the equilibrium of a policy game, and illustrated their properties. From a normative point of view, this line of research thus emphasizes the benefits of commitment relative to discretion, i.e., the benefit of having institutions that make it difficult to renege on policy promises.

This pioneering work was developed by two macroeconomists. Hence, much attention was devoted to issues of expectations formation in a dynamic setting. The connections with the game-theoretic literature and the notion of subgame perfection in a game only became apparent later, in the early 1980s. But once the game-theoretic formulation became widespread and policy decisions were viewed as the equilibrium outcome of a game, it was natural to enrich the positive content of such a game by bringing politics and institutions into the picture. The policymaker's incentives and constraints originate in the political process and, thus, macroeconomics began to pay attention to political phenomena and their implications for policy choice in rational expectations equilibrium. ${ }^{1}$ A new line of research evolved, that tries to understand why governments behave the way they do. Policy formation and its economic consequences are jointly studied from a positive perspective, combining insights from macroeconomics, game theory and political science.

In retrospect, a crucial step in the evolution of this line of research was the idea that optimal policy rules may lack credibility if they are chosen sequentially. It was here, with the notion of "time inconsistency" of optimal policy rules, that the foundations were laid for all subsequent research on endogenous macroeconomic policy, credibility and politics.

\section{A Brief History of the Idea of Time Inconsistency}

The notion of time inconsistency of economic policy has its roots in three lines of research that preceded the innovative paper of Kydland and Prescott. The first and earliest set of contributions concerns the analysis of inconsistencies in intertemporal consumer choices. The second is the early debate on rules vs. discretion in economic policy. The third is the analysis of

\footnotetext{
${ }^{1}$ Naturally, economists studying other policy areas (most notably trade policy and public finance) had already started to pay attention to politics well before this became common practice among macroeconomists - although not always with a game-theoretic formulation, nor under the assumption of individual rationality.
} 
dynamic games. Here, I briefly summarise the main contributions in these three lines of research.

\section{Time-inconsistent Preferences in Individual Choice}

The concept of "time inconsistency" was used very early on to describe the changing plans of a consumer who regrets his early choices. Allais (1947) is probably the first contribution on these issues. He considered a consumer with exogenously changing tastes. In 1955, Strotz analysed the intertemporal choices of a consumer who discounts future consumption. The outcome of this choice is a consumption plan over the entire planning horizon. Strotz asked under what conditions an optimising consumer would want to adhere to his earlier consumption plan, if he is allowed to reconsider such a plan at later dates. His answer was that a time inconsistency arises if and only if the individual discounts the utility of future consumption with a non-exponential discount function. Intuitively, what is crucial for time consistency is that the discount rate applied to future utility should depend on the time distance from the present date, not on the calendar date. With exponential discounting, all future rates are discounted at a constant rate of interest, and this ensures time consistency. Strotz and some of the subsequent literature also considered implications of time inconsistency, i.e., the value of precommitment and how to characterise a time-consistent solution as the equilibrium outcome of a game between decision makers at different points in time; see, in particular, Pollak (1968). ${ }^{2}$ None of this early work had anything to do with policy choice or credibility, however. It is the same decision maker who chooses at different points in time, and there is no distinction between a government and a private sector. Kydland and Prescott (1977) quote this early literature and borrow some key concepts from it, in particular the notion of time inconsistency.

As far as I know, the notion of a time-consistent equilibrium as a game between different individuals who make decisions sequentially over time appears for the first time in Phelps and Pollak (1968). This remarkable paper studies an overlapping generation's economy where generations live one period and are linked by some degree of altruism. Each generation chooses how much to save, the amount saved is then inherited by the next generation, which in turn chooses savings, and so on ad infinitum. The paper contrasts different equilibria: what they call the first-best equilibrium, in which the first generation chooses the time path of consumption for the indefinite future, as if it had full commitment, and a Nash equilibrium between the different generations, when

\footnotetext{
${ }^{2}$ These ideas have been given new life in recent research in behavioural economics. See, in particular, Laibson and Harris (2001) on hyperbolic discounting.
} 
they choose sequentially over time. Imperfect altruism makes these equilibria different from each other. This notion of equilibrium is then invoked by Kydland and Prescott when characterising what they call the time-consistent equilibrium. Here, again, there is no discussion of economic policy, nor of credibility. This paper, like that by Strotz (1956), is an important precursor of the solution concepts used in the later literature on credibility. But we had to await the contribution of Kydland and Prescott to find an analysis of the substantive economic policy issues.

\section{The Early Debate on Rules versus Discretion}

Another related early literature is the debate on rules versus discretion in macroeconomic policy. In the late 1940s and 1950s, Friedman and Simon were arguing forcefully in favour of a stable and non-activist policy regime, where monetary and fiscal policy would obey simple rules; see, in particular, Friedman (1948). These contributions are not quantitative or analytical, though they certainly had a large influence on later work. The arguments in favour of simple and stable policy rules set out by Friedman and Simon also concern expectations formation; but the ideas of credibility, time inconsistency, or more generally suggestive of a game-theoretic formulation, are not prominent in these writings.

A paper worth mentioning, as a precursor of later formal work on credibility, is Auernheimer (1974). Auernheimer writes in the Chicago tradition and studies the optimal quantity of money. He notes that the results on optimal seigniorage under perfect foresight apply to the steady state, but require some special constraints on what the government is allowed to do in the transition, to rule out optimal inflation surprises. He falls short of developing his ideas in terms of time inconsistency, however; nor does he discuss the distinction between commitment and discretion.

Auernheimer's (1974) insights were then used as a starting point by Calvo $(1978 \mathrm{a}, \mathrm{b})$ in his important papers on the time inconsistency of the optimal inflation tax. Writing at about the same time as Kydland and Prescott, Calvo extends Auernheimer (1974) by fully working out the government's optimisation problem in general equilibrium and points out that the optimal monetary policy rule is time inconsistent if the government lacks nondistorting taxes. He also characterises some features of the time-consistent solution, along the lines of Phelps and Pollak (1968).

\section{Dynamic Policy Games}

The third group of related earlier contributions is more methodological, and focuses on dynamic games. Finn Kydland's dissertation at Carnegie-Mellon University studied dynamic games of policy coordination. Two published 
chapters analysed linear-quadratic dynamic games-Kydland (1975, 1977). Although they have little empirical content, these papers provide a very clear comparison of open-loop and feedback strategies, as well as a discussion of the dominant player's games. Kydland (1975) is the first paper by an economist to clarify these issues. ${ }^{3}$ The analysis of the dominant player game, particularly developed in Kydland (1977), is more important. Kydland notes that the dominant player open-loop or closed-loop solutions are time inconsistent, and explicitly interprets this inconsistency as lack of credibility. On this basis, he argues in favour of the feedback solution as the appropriate solution concept in dynamic games with a dominant player, noting that it is self-enforcing. ${ }^{4}$

Though conceptually very clear, these papers by Kydland still lack concrete economic content. Moreover, they do not attempt to identify the government with the dominant player, nor do they draw general implications for the theory of economic policy. More important, there is no exhaustive discussion of rational expectations, or of private expectations formation. These papers are important methodological contributions that clarify and compare alternative solution concepts. They also suggest that the author had a deep and complete understanding of the issue of time inconsistency. But they do not yet draw all the relevant implications discussed in the next section. $^{5}$

\section{Rules versus Discretion and Policy Credibility}

The major step forward in this line of research is to be found in Kydland and Prescott (1977). Drawing on the conceptual insights of earlier methodological contributions, the notion of rational expectations formulated by Lucas, and the more intuitive normative arguments of Friedman and Simon in favour of simple rules, this paper reaches some startling yet logically compelling and very general conclusions. In a general dynamic setting, optimal policy rules are not credible, because they are "time inconsistent": if the policy rule is believed and used to form expectations of future policy by private agents, the government has an incentive to deviate from it later on, inducing policy "surprises". In an equilibrium with rational private agents, such policy surprises are ruled out. The equilibrium policy rule

\footnotetext{
${ }^{3}$ As Kydland himself acknowledged, the distinction between open-loop and feedback strategies was already clear at that time to mathematicians working on game theory.

${ }^{4}$ Kydland also quotes earlier work by Simaan and Cruz (1973a,b).

${ }^{5}$ Other earlier contributions that discuss ideas closely related to time inconsistency, without a formal systematic analysis however, are Buchanan's (1975) discussion of the "Samaritan's dilemma", Coase's (1972) analysis of the pricing problem of a durable-good monopolist, and Elster (1977).
} 
must be self-enforcing, like the feedback equilibrium discussed by Kydland. But once this solution concept is adopted, the policy rule creates a lower overall level of welfare. The way out of this trap is to commit to a policy rule in advance. Discretion, namely a setting where policy is chosen sequentially over time, suffers from lack of credibility. Irreversible commitments are valuable, because they lend credibility to policy and enable the policymaker to influence private sector expectations.

The contribution of Kydland and Prescott can be explained and summarised as follows. Consider a situation where there is conflict of interest between the government and private economic agents. This conflict can arise even if the government and the private sector have identical preferences: if there are relevant economic externalities or if the government lacks nondistorting policy instruments, the equilibrium allocation is inefficient from the government point of view. Whenever there is such a conflict of interest, the government will use economic policy to influence private sector behaviour and implement its preferred allocation. Formally, the government is the dominant player (or Stackelberg leader) in a game with (atomistic or large) private agents. In a dynamic economy, private behaviour depends on the expectations of future economic policy. Hence, the ability to influence expectations is crucial for policy success.

If the policy rule is selected by the government once and for all, without subsequent re-planning, then rational private agents will adapt their expectations taking this policy rule into account, and this is the end of the story. If, instead, policy choice is sequential, and it is made period after period, then the policymaker is subject to an incentive constraint. Private expectations will not adjust to any pre-announced policy rule. Rational expectations will instead reflect the equilibrium policy choice of future periods. Current policy decisions can only influence future expectations to the extent that current policies affect future equilibrium outcomes. This incentive constraint limits what the government can achieve and results in reduced government welfare, compared to the situation in which binding policy commitments are feasible.

Kydland and Prescott (1977) illustrated their result with several examples where policies implemented by a benevolent government are likely to suffer from time inconsistency: social insurance against natural disasters, patent protection for inventions, a simple monetary policy model of inflation and unemployment, and an optimal taxation problem in a dynamic economy. In all these examples, a successful policy must influence private sector expectations, but time inconsistency prevents this from happening. For instance, in the case of social insurance against natural disasters, there is an obvious moral hazard problem. If citizens expect government assistance in the event of a natural disaster, they are more likely to take risks and settle in areas prone to calamities. To discourage moral hazard, an optimal government policy must promise only limited relief in the event of a natural disaster. But 
this promise is not credible: if the natural disaster occurs, a benevolent government will forget its early promises and provide full insurance. Expectations of this future generosity induce private settlements in risky areas without adequate private protection and a suboptimal outcome is attained, where private agents undertake excessive risks and the government is then forced to provide excessive social insurance.

The monetary policy example addressed by Kydland and Prescott is particularly well known, also thanks to its popularisation by Barro and Gordon (1983a,b). Consider an expectations-augmented Phillips curve model with sticky nominal wages. Here, monetary policy can reduce unemployment below the natural rate only if it creates a rate of inflation higher than expected. ${ }^{6}$ In a static version of this model, current equilibrium inflation does not depend on past policy choices. Hence, the incentive constraint implies that expected inflation is also a constant that must be taken as given by the policymaker setting monetary policy today. Intuitively, when monetary policy is set, nominal wages are already fixed by existing contracts and incorporate some expectations of forthcoming inflation. This implies that, when policy is set, there is a trade-off between inflation and unemployment: higher inflation corresponds to higher unexpected inflation and lower real wages and, hence, lower unemployment. The optimal policy, subject to this incentive constraint, thus equates the marginal cost of higher inflation with the marginal benefit of reduced unemployment. If the policymaker's goal is to reduce unemployment below the natural rate, this then results in a positive inflation rate (or, more generally, in inflation above the target rate). But this policy is fully anticipated by private agents and, in equilibrium, expected inflation equals actual inflation. Hence, equilibrium unemployment remains equal to the natural rate as long as there is an inflation bias, i.e., equilibrium inflation is consistently above the target.

This celebrated inflation bias result arises because the policymaker would like to reduce unemployment below the natural rate. But, as subsequent research has made clear, lack of credibility results in lower welfare, even if the policymaker's goal is to stabilize unemployment fluctuations around the natural rate and keep inflation close to a target, so that there is no systematic inflation bias. Suppose, for instance, that equilibrium unemployment depends on expectations of future inflation (as in sticky price newKeynesian models), rather than on current expected inflation. The incentive constraint continues to imply a constant expected inflation. But now, even without giving rise to a systematic inflation bias, this constraint limits the policymaker's ability to stabilise the economy in the face of aggregate supply-side shocks. Intuitively, the incentive constraint prevents expected

\footnotetext{
${ }^{6}$ This model implicitly assumes that nominal wages are set one period in advance, based on expectations of the price level that will prevail in the next period; cf. Fischer (1977).
} 
inflation from optimally responding to the shocks that hit the economy, which reduces social welfare.

In more general dynamic models, equilibrium expectations of future policy variables will be functions of state variables and available information. But with sequential policy choice, the incentive constraint still implies that expectations do not respond to current policies as they would in a situation with binding commitments. Hence, it remains true that sequential policymaking results in lower social welfare, as compared to a situation with binding policy commitments. Lack of credibility is endemic to virtually any dynamic policy choice problem, and has relevant positive and normative consequences in a variety of situations.

Subsequent research also pointed out a second general result. The incentive constraint due to lack of credibility also implies that, in general, there are multiple equilibria. Public policy is determined by private sector expectations, rather than the other way around. For instance, the ex-post optimal tax rate on private wealth may depend on aggregate savings: if savings are high, the tax base is large and a benevolent government can raise a great deal of revenue with a low tax rate on wealth; but if savings are low, the tax base is small and the government may be forced to impose a much higher tax rate. In equilibrium, aggregate savings depend on expectations of the forthcoming tax rate. This creates a strategic complementarity that can give rise to multiple equilibria. Hence, a government can be forced into financial crisis or sudden macroeconomic instability by an adverse shift in expectations. The shift in expectations is entirely rational and self-fulfilling because agents know that policy choices are sequential and determined by aggregate economic behaviour. In other words, in an economy where policy choice is sequential, there can be a fundamental indeterminacy. This insight has been exploited by a large literature on speculative attacks and confidence crises.

The idea that lack of credibility imposes a binding constraint on policymakers has several important implications. From a normative point of view, it suggests that there is value in enabling the government to undertake policy commitments. This point is obviously relevant for the design of institutions. Constitutional provisions making it difficult for a government to renege on its previous contractual obligations perform a crucial function in this respect. With regard to monetary policy, international agreements to fix the exchange rate, or the delegation of monetary policy choice to an independent agency with well-defined priorities and objectives, also reduce the scope for the pursuit of discretionary and whimsical goals, and can thus increase monetary policy credibility. More generally, the design of policy institutions has important implications for how binding the incentive constraint is in relation

\footnotetext{
${ }^{7}$ This point is discussed by Woodford (2003).
} 
to policy credibility. Institutions ought to be designed to relax this incentive constraint, so as to enhance credibility. Such implications have clearly had a concrete counterpart in real-world debates and political decisions.

There is also a second important implication: a positive theory of how policy decisions are made is an integral part of the description of an economic equilibrium and, hence, of economic analysis. Without such positive theory, private sector expectations cannot be pinned down and economic theory becomes incomplete. We cannot simply postulate any policy rule and investigate its properties, assuming that it will be fully believed by rational private agents. The analysis of how the economy reacts to a policy rule cannot be separated from the positive analysis of how policy choices are made. Both exercises are part of the same research programme. Clearly, this implication is particularly relevant in macroeconomics, because of the dynamic nature of the environment and the crucial role played by expectations.

\section{Subsequent Evolution in the Theory of Macroeconomic Policy}

Once its normative and positive policy implications became clear, the idea of time inconsistency generated a great deal of interest and a lively debate among macroeconomists. ${ }^{8}$ Here, I briefly summarise two lines of research that evolved from Kydland and Prescott's fundamental insights.

\section{Game-theoretic Analysis of Macroeconomic Policy}

The first macroeconomists who wrote on policy credibility did not see the link with the notion of subgame perfection as a refinement of Nash equilibrium. Kydland and Prescott (1977) used different equilibrium concepts in the different models that appeared in their paper. In one model, they rely on the Nash equilibrium. In another model, the solution is based on sequential rationality (the expectations of all agents are consistent with future equilibrium behaviour, for all possible current states including those resulting from out-of-equilibrium actions). Yet, neither Kydland and Prescott (1977) nor the other macroeconomists who wrote about this topic in the late 1970s refer to Selten's (1965) subgame-perfect equilibrium concept.

In the early 1980s, new developments in game theory and industrial organisation also focused attention on the role of expectations formation in a strategic setting. The literature on reputation can be traced back to the theory of super-games elaborated by James Friedman in the early 1970s, but

\footnotetext{
${ }^{8}$ This early debate did not always contribute to more clarity. But a very clear paper by Fischer (1980) on time inconsistency and capital taxation dispelled any remaining confusion.
} 
received a new impetus in the early 1980s thanks to the work of Kreps, Wilson, Milgrom and Roberts, among others. Once the connection between time inconsistency and the game-theoretic formulation of credibility became clear, there was a rapid proliferation of interesting research applying various game-theoretic tools to formulate a positive theory of monetary and fiscal policy. ${ }^{9}$

Exploiting these game-theoretic insights, a series of influential papers by Barro and Gordon $(1983 a, b)$ carried the idea of Kydland and Prescott one step forward, using it as the foundation for a positive theory of economic policy. Lack of credibility, interpreted as time inconsistency, offered a natural explanation of why many countries end up with prolonged and high inflation, despite repeated promises to fight it. Barro and Gordon embedded the simple Phillips curve model of monetary policy illustrated by Kydland and Prescott in a repeated game and discussed central bank reputation, along the lines of early contributions in the industrial organisation literature (in particular by James Friedman). Other papers formulated models of reputation based on learning and asymmetric information between the policymaker and the rest of the economy. The incentive to preserve its reputation could strengthen central bank credibility and mitigate the timeinconsistency problem, although with specific caveats.

The literature that developed in the 1980s and 1990s went on to discuss many other issues in economic policy where lack of credibility has important positive and normative implications. Prominent among these are the role of public debt management in shaping the credibility of public financial policies, the protectionist bias in trade policy that also results from lack of credibility and, as already mentioned, the possibility of confidence crises on sovereign debt or of speculative attacks on fixed exchange rates. The idea of time inconsistency provided a turning point and laid the foundations for all this subsequent work.

The finding that benevolent and well-informed policymakers could implement highly suboptimal policies just because they lacked credibility also spurred a wave of research on institutional reforms. Rogoff (1985) pointed out that strategic delegation of monetary policy to an independent and conservative central banker could restore some credibility. Subsequent research refined this insight by studying the properties of optimal monetary regimes and drawing practical lessons for real-world monetary institutions. These ideas left the ivory tower of academic research and had a lasting impact on real-world institutions and the formulation of central bank strategies.

\footnotetext{
${ }^{9}$ Among the first contributions that relate time consistency of macroeconomic policy and subgame perfection are Gale (1982) and Lucas and Stokey (1983).
} 


\section{Politics and Economic Policy}

A last and even more recent turn of the research on macroeconomic policy is the attempt to incorporate and study political determinants of economic policy. Even though there are some important earlier ideas, the main contributions to this line of research in macroeconomic policy analysis have been developed since the second half of the 1980s or later. If rational expectations of future policy choices ought to be based on the equilibrium outcomes of a policy game, it is clear that politics and political incentives are essential ingredients of such a game. A recent literature takes this perspective, abandoning the assumption maintained by Kydland and Prescott that policy is set by a benevolent government. This is a major departure that raises important new questions: how are conflicting interests aggregated, what motivates politicians, what enables citizens to induce their representatives to pursue a common good, and so on. This new literature has more empirical content, and there is a tight interaction between theoretical progress and empirical work. Moreover, this line of research extends well beyond macroeconomics, and deals with a host of other policy areas such as trade policy, public finance, regulation, and so on. Several recent books review and discuss this new line of research, at the frontier between economics and political science. ${ }^{10}$

\section{Concluding Remarks}

With their innovative paper, Kydland and Prescott have made fundamental contributions at three levels: (i) At the methodological level, they have extended and integrated the notion of rational expectations formulated by Muth and Lucas with a game-theoretic formulation: rational expectations of future policy must be based on a complete (and out-of-equilibrium) analysis of the policymaker's incentives and constraints. (ii) At a positive level, the incentive constraint that results from this more stringent view of rational expectations can explain suboptimal government behaviour, such as persistently high inflation, as an equilibrium phenomenon. This positive analysis is particularly valuable for understanding observed monetary phenomena and macroeconomic policy choices in industrial as well as developing countries. The positive implications of this analysis also launched a new research programme, at the frontier between economics and political science, that seeks to explain observed government behaviour with the standard tools of economists. (iii) At a normative level, this line of research has clarified why

\footnotetext{
${ }^{10}$ See, in particular, Drazen (2000), Grossman and Helpman (2001) and Persson and Tabellini (2000).
} 
some institutions governing policy formation are better than others and, more generally, which institutional properties are desirable and conducive to effective and credible decision making over public policy and monetary policy in particular.

These contributions are the results of a research effort that lasted several years, involving many economists, and which is still in progress and remains extremely promising. But the germs and the substance of these ideas, at all three levels, are present in the seminal paper by Kydland and Prescott (1977) and were developed in this paper for the first time.

\section{References}

Allais, M. (1947), Economie et Intérêt, Imprimerie National, Paris.

Auernheimer, L. (1974), The Honest Government's Guide to the Revenue from the Creation of Money, Journal of Political Economy 82, 598-606.

Barro, R. J. and Gordon, D. B. (1983a), A Positive Theory of Monetary Policy in a Natural-rate Model, Journal of Political Economy 91, 589-610.

Barro, R. J. and Gordon, D. B. (1983b), Rules, Discretion and Reputation in a Model of Monetary Policy, Journal of Monetary Economy 12, 101-120.

Buchanan, J. (1975), The Samaritan's Dilemma, in E. Phelps (ed.), Altruism, Morality and Economic Theory, Russell Sage Foundation, New York.

Calvo, G. (1978a), On the Time Consistency of Optimal Policy in a Monetary Economy, Econometrica 6, 1411-1428.

Calvo, G. (1978b), Optimal Seigniorage from Money Creation, Journal of Monetary Economy $4,503-517$.

Coase, R. (1972), Durability and Monopoly, Journal of Law and Economics 15, 147-180.

Drazen, A. (2000), Political Economy in Macroeconomics, Princeton University Press, Princeton, NJ.

Elster, J. (1977), Ulysses and the Sirens: A Theory of Imperfect Rationality, Social Science Information 16, 469-526.

Fischer, S. (1977), Long-term Contracts, Rational Expectations and the Optimal Money Supply Rule, Journal of Political Economy 85, 163-190.

Fischer, S. (1980), Dynamic Inconsistency, Cooperation and the Benevolent Dissembling Government, Journal of Economic Dynamics and Control 2, 93-107.

Friedman, M. (1948), A Monetary and Fiscal Framework for Economic Stabilization, American Economic Review 38, 245-264.

Gale, D. (1982), Money in Equilibrium, Cambridge University Press, Cambridge.

Grossman, G. and Helpman, E. (2001), Special Interest Politics, MIT Press, Cambridge, MA.

Kydland, F. (1975), Non-cooperative and Dominant Player Solutions in Discrete Dynamics Games, International Economic Review 16, 312-335.

Kydland, F. (1977), Equilibrium Solutions in Dynamic Dominant-player Models, Journal of Economic Theory 15, 307-324.

Kydland, F. and Prescott, E. C. (1977), Rules Rather than Discretion: The Inconsistency of Optimal Plans, Journal of Political Economy 85, 473-491.

Kydland, F. and Prescott, E. C. (1980), Dynamic Optimal Taxation, Rational Expectations, and Optimal Control, Journal of Economic Dynamics and Control 2, 79-91.

Laibson, D. and Harris, C. (2001), Dynamic Choices of Hyperbolic Consumers, Econometrica 69, 935-957. 
Lucas, R. E. and Stokey, N. L. (1983), Optimal Fiscal and Monetary Policy in an Economy without Capital, Journal of Monetary Economics 12, 55-94.

Persson, T. and Tabellini, G. (2000), Political Economics: Explaining Economic Policy, MIT Press, Cambridge, MA.

Phelps, E. and Pollak, R. A. (1968), On Second Best National Saving and Game-equilibrium Growth, Review of Economic Studies 35, 185-199.

Pollak, R. A. (1968), Consistent Planning, Review of Economic Studies 35, 201-208.

Rogoff, K. (1985), The Optimal Degree of Commitment to an Intermediate Monetary Target, Quarterly Journal of Economics 100, 1169-1190.

Selten, R. (1965), Spieltheoretische Behandlung eines Oligopolmodells mit Nachtragefragheit, Zeitschrift für die gesante Staatswissenschaft 121, 301-324 and 667-689.

Simaan, M. and Cruz, J. B. Jr. (1973a), On the Stackelberg Strategy in Non-zero-sum-games, Journal of Optimization Theory and Applications 9, 533-555.

Simaan, M. and Cruz, J. B. Jr. (1973b), Additional Aspects of the Stackelberg Strategy in Nonzero-sum-games, Journal of Optimization Theory and Applications 9, 613-626.

Woodford, M. (2003), Optimal Interest Rate Smoothing, Review of Economic Studies 70, 861-886. 